\title{
Alumni Grassroots Leadership Enables Sponsored Course Development
}

\section{Dr. Vladimir I. Prodanov, California Polytechnic State University, San Luis Obispo}

Vlad Prodanov received M.S. and Ph.D. degrees, both in electrical engineering, from the State University of New York at Stony Brook in 1995 and 1997 respectively. He was with Bell Laboratories, Lucent Technologies from 1997 until 2000 and Agere Systems from 2000 to 2004. From 2004 to 2008 he was a member of MHI Consulting. He joined the EE Dept., Cal Poly, San Luis Obispo, CA in 2008 where he is now a tenured Associate Professor. Dr. Prodanov has worked on various electronic systems for communications and contributed to two dozen peer-reviewed publications, three book chapters, and twenty granted U.S. patents. Dr. Prodanov is a recipient of several teaching awards.

\section{John Greene, Maxim Integrated}

John is an alumnus from Cal Poly receiving both his B.S. and M.S. in electrical engineering, along with a minor in physics during his tenure at Cal Poly. Post graduation, he took an application engineering position at Maxim Integrated and has helped establish a stronger university relations program by encouraging sponsorship of universities to create new courses. 


\title{
Alumni Grassroots Leadership enables Sponsored Course Development
}

\begin{abstract}
This paper demonstrates the importance of alumni voluntarism in creating experiential learning opportunities for future students while also facilitating the professional development of a faculty member. Specifically, the collaboration between two recent graduates and their former college professor resulted in the development of a new 400-level elective class containing both a lecture component and a lab component. Because of alumni efforts, the lab will use state-of-art hardware allowing students' exploration of various concepts related to sensing and IoT (Internet of Things). The generous support of the employer effectively eliminates the financial burden to students and enables faculty professional development. Also discussed are some aspects of engineering education and relevant trends in alumni giving.
\end{abstract}

Keywords: alumni, voluntarism, training, ABET, laboratory, collaboration, experiential learning

\section{Introduction}

Cal Poly is a predominantly undergraduate institution widely recognized for its excellent engineering programs. With an enrollment of over 5,800 undergraduate students and 280 graduate students, the College of Engineering is a major supplier of engineering talent in California. As most of our baccalaureate recipients begin their careers in industry and do not pursue graduate degrees, our programs strive to keep a curriculum aligned with industrial practice.

Both the structure and the content of the curriculum determine the alignment. Typically, a curriculum structure which strikes a meaningful balance between analytical and experiential learning is needed [1]. A lab-based curriculum is regarded well in the industry because it offers experiential reinforcement of engineering theory while demonstrating the limitations of purely analytic approaches to engineering problems. The added benefit of a well-equipped lab is students' exposure to tools and techniques they would encounter in the industry.

Most Cal Poly EE courses (15 of 19) include a lab component giving the students practice in the application of theory. It also introduces students to the methodologies and tools used in the design, analysis, modeling, and testing of circuits, electronics, and systems. This lab-intensive structure is commensurate with the University's 'learn-by-doing' philosophy. The same philosophy also extends to most of the digital systems and computer design courses in the curriculum which are taught in a 'studio' classroom format.

In the following, we will briefly review the current role of alumni in aligning educational outcomes with industry needs. While the discussion is concerned with the current practices in the 
electrical engineering department at Cal Poly, the literature suggests they also reflect the practices of other similar programs.

Within the context of program accreditation by The Accreditation Board for Engineering and Technology (ABET), alumni contribute in two important ways:

$>$ By serving on Industrial Advisory Boards (IAB);

By responding to alumni surveys;

While AIB members need not be Cal Poly graduates many of them are accomplished alumni with many years of professional experience. As discussed by Verma [2], the IAB is the customer's voice within the ABET process and serves to make the program more relevant to the industry. The IAB forms with the department an important strategic partnership providing a window into the changing dynamics of the industrial sector.

ABET-related surveys target graduates that have entered the workforce in the last 3-5 years. The results from the survey provide an indication of the relevance of program outcomes through the work experiences and accomplishments of recent graduates. Despite the limitations, alumni surveys remain an important tool for indirect program assessment [3].

Alumni also contribute to the success of our program in other ways; for example:

By facilitating internships and co-ops via participation in career fairs;

By way of monetary gifts;

Cal Poly annually hosts two career fairs attended by over 150 companies and organizations. Some participating alumni use the opportunity to showcase the technology they work on by delivering technical seminars. While student internships do not translate into program improvement, they have a positive impact on student academic performance and immediate employability. Also, internships help with the 'crystallization' of career plans and professional identity of students [4].

In our college the procurement of lab equipment, conference attendance, and professional memberships of the faculty are funded mostly from discretionary accounts. Because gifts make a sizable portion of departmental discretionary account one could say our benefactors indirectly support our labs and partially support the professional development of faculty.

This paper discusses an alternative approach to alumni giving with a direct impact upon the experiential learning environment. 


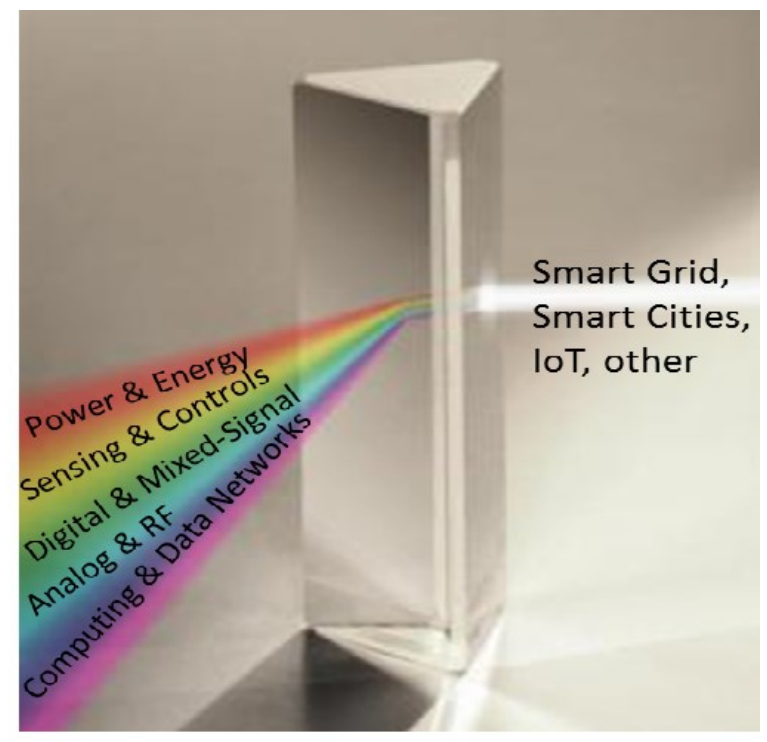

Figure 1: Light analogy of the current state of technology. The EE curriculum at senior and MS level traditionally resides to the left deeper into the individual technical fields while the changes we experience today are arguably fueled by the confluence.

\section{How Can Alumni Help Realize the Full Potential of a Lab-Intensive Curriculum?}

While our program has a long history of learn-by-doing, the technology evolution in the last decade challenges instructor ability to deliver industry-relevant laboratory experience; this is especially true in advanced (400-level and 500-level) hardware-based courses. In the era where one square-inch of board space packs more technology than we cover in the entire EE curriculum (no exaggeration), technology outpaces the rate of instructors' professional development. This is mostly due to the confluence of different technical fields. As depicted in the prism analogy in Figure 1 such convergence is observed in many industry sectors creating new system-of-systems paradigms. In practical terms, instructors may be able to teach 'point-of-confluence' courses and explain how key concepts covered in lower-level courses are reflected in the current state-of-art, but few have the skills or the equipment to create hardware platforms that support technicallybroad learning outcomes.

A solution to the above issue is found in the collaboration between an engineering instructor and an engineering practitioner. From the practitioner's point of view, the collaboration resembles 'applications engineering' where together with a client he/she defines a system that meets requirements within constraints imposed by available technology. Then, the engineer supported by his organization designs and demonstrates a prototype subsequently used in the lab. From the faculty point of view, the collaboration is an opportunity to learn about new products and acquire skills needed to evaluate and use the lab hardware. Such an engagement has a significant and long-lasting positive effect on the program because it simultaneously addresses two educational 
challenges - the creation of hardware containing state-of-art components and development of a faculty with relevant technical skills.

Since the described product development is resource-intensive, such a relationship would need the support of the employer; the support amounts to a charitable contribution to the program. It is also expected the engineer will do the development on his/her own time - an act of voluntarism.

The previously described 'applications engineering' process to laboratory development and faculty support is not 'just theory'. The strategy was recently employed in the development of a new 400-level IoT course to be offered in the Spring Quarter of 2018. A brief description of this effort is presented next.

\section{Alumni Develop Hardware for a New 400-level Lab Course}

Recently the lead author of this paper qualified for a sabbatical leave and the college enthusiastically approved the proposal - a 400-level elective in networked sensors. The goal was to create a lecture course that studies the state-of-art in sensor and communication technologies and reveals techniques that have stood the test of time. The effort is best captured by D. Wilson's recommendation of what instructor should do in the face of a major technology change "... ferret out what represents an "enduring understanding" and differentiate these from transitional technology, then teach these fundamentals well through the lens of modern technology." [5]. Having a lab where students could get the first-hand experience with cutting-edge technology was viewed highly beneficial, but creating such a hardware platform is beyond the time constraints and financial capability of the instructor.

Simultaneously a recent Masters-level graduate, employed by one of our IAB member companies, approached the department head with a proposal of a lab with IoT emphasis. He had previously secured the support of his employer and was willing to manage the project, donating his time and technical talents. He also recruited a former classmate who graduated a few years earlier with a BSEE degree; this person was also gainfully employed by the same company and was willing to volunteer. Over the summer, the team completed the hardware and gave the instructor three prototypes allowing him ample time to prepare for the lab; meanwhile, both the lecture and the lab were approved by the university and scheduled for the Spring quarter of 2018.

Being a (mostly) undergraduate institution we experience a severe shortage of qualified help for 400-level and 500-level courses. This means that when an advanced class is offered for the first time the instructor teaches all lecture and lab sections without TA support. This concern was resolved by having a summer intern assigned to the project. The student, a senior in our department, developed some of the firmware for the project and acquired the necessary skills to serve as a lab TA for the new lab course; the TA position will be financed by the department.

The format of the partnership allowed us to meet the needs of the stakeholders while minimizing bias in course coverage. Specifically, the instructor defined a system based on students' learning 
outcomes whereas the two alumni chose the proper system partition, the form-factor of the boards, and the architecture of each board. Several iterations followed with the goal to support the learning outcomes and use parts that best showcase the company products while also accounting for software availability and students' level of preparation. Having two contributors that were recent graduates of our program proved invaluable. They had first-hand experience with the curriculum and a clear appreciation of its strengths and weaknesses. Also, both have developed a good working relationship with the faculty member having previously taken several lecture and lab courses with him.

Finally, the sponsoring company also funded instructor's professional development account. The amount matches his income loss due to the 2-quarter sabbatical (only the 1st quarter is fully funded) and allows for equipment and textbook purchases, conference and workshop attendance, and hiring of research assistants. This generous gift enables future professional development much beyond the learning that resulted from the lab hardware development.

4. Important Trends in Giving: A Related Discussion

Many authors have examined the engagement habits of young college-educated adults and found a significant departure from those of previous generations.

Surprisingly and despite its uniqueness, our case exemplifies current trends in alumni giving. This includes a willingness to donate towards a specific project, to directly contribute and even recruit one's friends. The details are provided below.

Research [6],[7] finds that alumni today respond poorly to non-specific fundraising campaigns, but many gladly donate to a specific cause. In his 2014 paper "Class Exodus", Allenby [6] reports that "alumni giving rate has dropped 50 percent over the last 20 years". Two reasons for the decline is the use of outdated 'give-back' campaigns in the face of ever-increasing education cost and over reliance on mega-gifts. To advancement organizations, Allenby recommends: "Tell stories about gift impact (and not just the impact of big gifts)...". A recent survey [7] of the engagement attitudes among millennials supports Allenby's argument. More than 55\% of the surveyed 2,2000 millennials would respond to a specific request. In contrast, fewer than $8 \%$ would respond to a general, non-specific call.

Another important trend identified in [7] is the rise of 'donor evangelism'. More than $2 / 3$ of the surveyed millennials would be willing to involve family members and friends. Strong reciprocity is also present; many the participants are willing to give if asked by a family member $(74.6 \%)$ or a friend $(62.8 \%)$.

While some things have changed, one aspect of giving and voluntarism remains the same: the benefactor expects to make a difference. This truism is often overlooked and occasionally rediscovered. For example, Weerts and Ronca [8] examined several competing theories and found that the 'expectation theory' best predicts alumni level of engagement. The authors 
summarize their findings as follows "... donors who are likely to give and volunteer at their alma mater expect to be involved in supporting the institution. In addition, they have developed a view that the institution needs their support". The authors admit they do not know how these expectations form. It is, however, reasonable to assume that personal relationships with faculty and the knowledge of how the gifts are being used play a positive role.

5. Conclusions

Our experience and the realities of alumni giving suggest we may witness more examples where a small group of alumni band together donating their time and technical talents in response to a specific call from a faculty member. This is especially true when the efforts relate to technical development under the auspices of the employer. With the proliferation of company matching gift programs 'crowdfunding' of small educational projects might also become common.

\section{References}

[1] J. Lamancusa, J. Zayas, A.Soyster, L. Morell, and J. Jorgensen, "The Learning Factory: Industry-Partnered Active Learning”, J. Eng. Education, Vol. 97, No. 1, pp. 355-361, 2008.

[2] A. Verma, "Role of Industrial Advisory Committee in the Assessment and Continuous Improvement Process of Engineering Technology Programs," Conference for Industry and Education Collaboration, ASEE, February 4-6, 2009, Orlando, Florida.

[3] A. Cabrera, J. Weerts and B. Zulick, "Alumni Survey: Three conceptualizations to alumni research," presented at Métodos de Análisis de la inserción laboral de los universitarios, Universidad de León, Spain, 2003.

[4] M. Hora, M. Wolfgram, and S. Thompson, "What do we know about the impact of internships on student outcomes?" research brief, Center for Research on College to Workforce Transitions (CCWT), Univ. Wisconsin-Medison.

[5] D. Wilson, "Training vs. education," American Printer, Vol.127, Issue 7, 2010.

[6] D. Allenby, "Class-Exodus", Retrieved Jan. 20, 2018, from https://annualgiving.com/

[7] "Millennial Donors: A Study of Millennial Giving and Engagement Habits," Retrieved Jan 20, 2018, from http://cdn.trustedpartner.com/docs/library/AchieveMCON2013/

MD10\%20Full\%20Report.pdf

[8] D. Weerts and J. Ronca, "Profiles of Supportive Alumni: Donors, Volunteers, and Those Who "Do It All ","International Journal of Educational Advancement, Vol.7, No.1, pp. 20-34, 2007. 